\title{
Resposta Superovulatória de Novilhas Mestiças Holandês-Zebu Tratadas com Somatotropina Bovina Recombinante (rbST)
}

\author{
Álan Maia Borges ${ }^{1}$, Ciro Alexandre Alves Torres ${ }^{2}$, José Reinaldo Mendes Ruas ${ }^{3}$, \\ Vicente Ribeiro Rocha Júnior ${ }^{1}$, Giovanni Ribeiro de Carvalho ${ }^{2}$
}

\begin{abstract}
RESUMO - O objetivo do experimento foi estudar o efeito do pré-tratamento com $500 \mathrm{mg}$ de sometribove (rbST) sobre a resposta superovulatória, o número e a qualidade dos embriões coletados de 26 novilhas mestiças holandês-zebu, divididas em dois tratamentos: $\mathrm{T} 1$ = tratadas com rbST $(\mathrm{n}=13)$ e $\mathrm{T} 2$ = controle $(\mathrm{n}=13)$. Foram feitas 13 superovulações entre o mês de setembro e o início de dezembro de 1997 (período 1) e 13 superovulações entre o final do mês dezembro de 1997 e fevereiro de 1998 (período 2), sendo que, para cada período, sete animais receberam $500 \mathrm{mg}$ de rbST (T1) por via subcutânea, no terceiro dia do ciclo estral, e seis animais (T2) não receberam medicação. Os animais foram superovulados com FSH a partir do $10^{\circ}$ dia do ciclo estral, e as coletas foram realizadas entre os dias 7 e 8 após a inseminação artificial. A resposta superovulatória, o número total de estruturas, o número de embriões viáveis, de não-viáveis e de ovócitos não foram afetados pelo tratamento com somatotropina bovina. Foram coletadas médias de 15,3 $\pm 9,5$ e 17,4 $\pm 10,9$ estruturas totais, 8,5 $\pm 8,3$ e 11,5 $\pm 10,0$ embriões viáveis, 4,6 \pm 4,7 e 3,4 $\pm 1,3$ embriões não-viáveis, $2,2 \pm 2,8$ e 2,8 \pm 4,0 ovócitos por coleta dos tratamentos 1 e 2 , respectivamente. As mórulas e os blastocistos jovens foram os estádios de desenvolvimento coletados em maior percentagem, entre o sétimo e oitavo dia após a inseminação artificial.
\end{abstract}

Palavras-chave: embriões, FSH, hormônio de crescimento

\section{Superovulatory Response of Holstein-Zebu Crossbred Heifers Treated with Recombinant Bovine Somatotropin (rbST)}

\begin{abstract}
The objective of the experiment was to study the effect of pretreatment with $500 \mathrm{mg}$ of sometribove (rbST) on superovulatory response, on number and embryos quality of twenty six crossbred holstein-zebu heifers, allocated into two treatments: $\mathrm{T} 1$ - treated with $\mathrm{rbST}(\mathrm{n}=13)$ and T2 - control $(\mathrm{n}=13)$. Thirteen superovulations were done between september and december of 1997 (period 1), and thirteen superovulations between the end of december 1997 and february of 1998 (period 2). For each period seven animals were injected with $500 \mathrm{mg} \mathrm{SC}$ sustained-release formulated rbST (T1) on day 3 of estrous cycle, while six animals (T2) did not receive any medication. The animals were superovulated with FSH on day 10, and the embryo collection were performed on day 7 or 8 after the artificial insemination (A.I.). Pretreatment of heifers with rbST did not increase the superovulatory response, total number of structures recover, viable and non viable embryos and ova per collection. The average of total number of structures recovered, viable and non viable embryos and ova per collection were: $15.3 \pm 9.5$ and $17.4 \pm 10.9 ; 8.5 \pm 8.3$ and $11.5 \pm 10.0 ; 4.6 \pm 4.7$ and $3.4 \pm 1.3 ; 2.2 \pm 2.8$ and $2.8 \pm 4.0$, respectively, for T1 and T2. The morulae and initial blastocists were recovered in greater percentage on day 7 or 8 after A.I.
\end{abstract}

Key Words: embryos, FSH, growth hormone

\section{Introdução}

O hormônio de crescimento bovino (bGH) foi um dos primeiros fatores de crescimento recombinantes ( $\mathrm{rbST}$ ) produzidos em grande escala para a indústria animal (BAUMAN, 1992), visando aumentar a produção de leite. O GH está envolvido no crescimento (GLUCKMAN et al., 1987) e na regulação de processos fisiológicos e metabólicos dos animais, por meio da síntese de IGF-I (fator de crescimento semelhante a insulina) e de proteínas transportadoras
(IGFBP), que são seus mediadores hormonais nos processos metabólicos (LUCY, 1996).

O rbST age em nível ovariano (TANNER e HAUSER, 1989), aumentando o número de folículos recrutados com diâmetros entre 2 e 5 mm (PAVLOK et al., 1996; HWANG et al., 1997), estimulando o crescimento e o desenvolvimento folicular (WEBB et al., 1994) e controlando a função do corpo lúteo (LUCY et al., 1993a,b). Seu mecanismo de ação é mediado pela elevação das concentrações intrafoliculares de IGF-I (GONG et al., 1991), que

\footnotetext{
${ }^{1}$ Aluno de Doutorado DZO/UFV. E.mail: alanmborges@hotmail.com; rochajuniorvr@hotmail.com

2 Professor do DZO/UFV. E.mail: ctorres@mail.ufv.br; giovanni@mail.ufv.br

3 Pesquisador da EPAMIG/CTZM - Viçosa (MG). E.mail: jrmruas@mail.ufv.br
} 
estimula a proliferação e a esteroidogênese pelas células da granulosa (LOBIE et al., 1990; GONG et al., 1994), a atividade da aromatase (ADASHI et al., 1985 a e b), além de prevenir ou retardar o processo de atresia folicular (MONDSCHEIN et al., 1989).

Os efeitos do rbST, via IGF-1, sobre a função ovariana também estão relacionados à potencialização (ERICKSON et al., 1989) e ao aumento da sensibilidade folicular às gonadotrofinas (GONG et al., 1996a; GONG e WEBB, 1996), além de modificar o padrão de aporte e utilização de nutrientes por tecidos dos órgãos genitais (PINTO ANDRADE et al., 1996).

A observação do sinergismo entre as gonadotrofinas e o rbST levaram vários pesquisadores a investigar sua combinação benéfica para o tratamento superovulatório. Os trabalhos de GRAY et al. (1993) e de GONG et al. (1993; 1996b) demonstram um aumento significativo no número de ovulações, e nos trabalhos de HERRLER et al. (1994) e LUCY (1996) observou-se maior número de embriões transferíveis por doadora tratada com rbST, com melhoria na resposta superovulatória e redução na variabilidade das respostas individuais, que, apesar de positivas, apresentaram magnitude variada.

O objetivo deste trabalho foi de medir a resposta superovulatória ao FSH: número e qualidade dos embriões coletados de doadoras tratadas com rbST.

\section{Material e Métodos}

O experimento foi realizado no Departamento de Zootecnia da Universidade Federal de Viçosa, no período de setembro de 1997 a fevereiro de 1998. Foram utilizadas 26 novilhas mestiças holandês-zebu, com escore da condição corporal entre 3,5 e 4,0 (escala de 1 a 5) e peso vivo ente 300 e $400 \mathrm{~kg}$. Todos os animais foram previamente submetidos a exame ginecológico por meio de palpação retal e vaginoscopia, sendo utilizados aqueles sem qualquer alteração clínica ou reprodutiva. As doadoras selecionadas foram mantidas em currais cimentados onde recebiam dieta à base de feno de coastcross ( $7 \mathrm{~kg} / \mathrm{cab} / \mathrm{dia})$ e concentrado ( $3 \mathrm{~kg} / \mathrm{cab} / \mathrm{dia})$, além de água e sal mineral à vontade, durante todo o período experimental. Antes de se iniciar o processo de superovulação observaram-se dois ciclos estrais das doadoras, para monitorar sua regularidade, e considerou-se normal aquele com duração de 18 a 24 dias. A identificação do estro foi feita duas vezes ao dia durante 1 hora, às $6 \mathrm{~h} 30$ e às $17 \mathrm{~h} 30$, com auxílio de rufião preparado por aderência peniana. Foram consideradas em estro as fêmeas que aceitavam a monta pelo rufião ou pelas companheiras de rebanho.

As 26 doadoras foram divididas aleatoriamente em dois lotes de treze animais, e os tratamentos superovulatórios foram realizados em dois períodos do ano: 13 superovulações entre o mês de setembro e o início de dezembro de 1997 (P1), e 13 superovulações entre o final do mês dezembro de 1997 e fevereiro de 1998 (P2). Para cada período, sete animais receberam $500 \mathrm{mg}$ de $\mathrm{rbST}^{1}$ (T1) por via subcutânea no terceiro dia do ciclo estral, e seis animais (controle) não receberam somatotropina. $\mathrm{O}$ tratamento superovulatório foi iniciado no $10^{\circ}$ dia do ciclo estral $($ estro $=$ dia 0$)$, e estendeu-se por quatro dias, totalizando oito aplicações em que se utilizou 500 unidades internacionais (UI) de hormônio folículo estimulante/hormônio luteinizante $(\mathrm{FSH} / \mathrm{LH})^{2}$, por via intramuscular, distribuídos em doses decrescentes conforme a Tabela 1. Juntamente com a $7^{\mathrm{a}}$ dose do hormônio ( $13^{\circ}$ dia, $19 \mathrm{~h}$ ), aplicou-se $0,5 \mathrm{mg}$ de um análogo de prostaglandina $\mathrm{F}_{2} \alpha\left(\right.$ cloprostenol $^{3}$ ), por via intramuscular. Após 24 horas desta aplicação, monitorou-se o estro até a identificação da primeira aceitação de monta. As inseminações artificiais foram realizadas a intervalos de 12,18 e 24 horas após a identificação do estro, utilizando-se sêmen ${ }^{4}$ de qualidade comprovada.

A coleta dos embriões foi feita pelo método não cirúrgico, sete a oito dias após a primeira inseminação artificial, com lavagem simultânea dos cornos uterinos. Antes do início da coleta, tentou-se a passagem da cérvix com o aplicador de sêmen protegido com a bainha francesa, objetivando direcionar e verificar o caminho de passagem do catéter de Foley. Os animais que não tiveram sua cérvix transposta foram eliminados dos procedimentos de coleta, sem a utilização do dilatador cervical. O meio de cultura utilizado na colheita foi a solução comercial de PBS modificado ${ }^{5}$

\footnotetext{
1 Sometribove Zinco - Lactotropin - Elanco Saúde Animal.

2 Pluset - Laboratórios Calier do Brasil Ltda.

3 Ciosin - Coopers do Brasil.

4 Sembra - Barretos.

5 Cultilab - Campinas.
}

Rev. bras. zootec., 30(5):1439-1444, 2001 


\begin{tabular}{lcc} 
Tabela 1 - Esquema de superovulação das doadoras, de \\
acordo com o dia do ciclo estral \\
Table 1 & $\begin{array}{c}\text { S Superovulatory protocol for donors of embryos, based } \\
\text { on day of estrus cycle }\end{array}$ \\
\hline $\begin{array}{l}\text { Dia do ciclo estral } \\
\text { Day of estrus cycle }\end{array}$ & \multicolumn{3}{c}{$\begin{array}{c}\text { Dose (UI) } \\
\text { Dose }\end{array}$} \\
\cline { 2 - 3 } & $7 \mathrm{~h}$ & $19 \mathrm{~h}$ \\
\hline 0 (Estro) & & \\
Estrus & & $100 \mathrm{UI}$ \\
$\bullet$ & & $100 \mathrm{UI}$ \\
$:$ & - & $50 \mathrm{UI}$ \\
10 & $100 \mathrm{UI}$ & $25 \mathrm{UI}+0,5 \mathrm{mg}$ \\
11 & $50 \mathrm{UI}$ & cloprostenol \\
12 & $50 \mathrm{UI}$ & - \\
13 & $25 \mathrm{UI}$ &
\end{tabular}

(DULBECCO e VOGT, modificado por WHITTINGHAN, 1971) aquecido a $37^{\circ} \mathrm{C}$.

As estruturas recuperadas foram classificadas quanto ao estádio de desenvolvimento de acordo com LINDNER e WRIGHT (1983), e quanto à sua morfologia segundo os parâmetros utilizados por KENNEDY et al. (1983) e, após identificados e classificados com o auxílio de um microscópio estereoscópio (aumento de 40 vezes), foram divididos em duas classes de qualidade: viáveis (embriões transferíveis) e não viáveis (embriões não transferíveis) para o processo de transferência a fresco.

Na análise estatística utilizou-se o programa SAEG 7.0, aplicando-se análise de variância para modelos lineares, a fim de se observarem as possíveis diferenças entre o número e a qualidade das estruturas coletadas em função dos dois tratamentos (controle e rbST).

\section{Resultados e Discussão}

Cerca de $88,5 \%$ dos animais $(\mathrm{n}=23)$ responderam ao tratamento com FSH e 11,5\% (n=3) não responderam. Estes dados estão de acordo com HAHN (1992) que demonstrou uma resposta negativa em até $30 \%$ dos animais.

Do total de vinte e seis animais experimentais conseguiu-se coletar estruturas em vinte deles e, do restante, três animais não responderam, um apresentou infecção uterina detectada no dia da coleta e em dois não se conseguiu transpor a cérvix, apesar de sua morfologia normal. O rbST não afetou a porcentagem de estruturas recuperadas à coleta, quando comparada àquela dos animais controle (92,3 e 84,6\%).

Em um animal recuperou-se apenas ovócitos, provavelmente por ter apresentado hipertermia (febre) nos dias próximos e durante o período da inseminação artificial, uma vez que o aumento da temperatura corporal pode prejudicar a viabilidade espermática e a maturação ovocitária (ROCHA et al., 1998).

Cerca de $80,76 \%(n=21)$ dos animais demonstraram sinais clínicos de estro em torno de 44 horas após a administração do luteolítico. Três animais (11,54\%) não manifestaram estro e não ovularam, apesar de demonstrarem bom crescimento folicular, enquanto outros dois $(7,7 \%)$ manifestaram estro após 60 horas da aplicação da prostaglandina (Tabela 2). Para DONALDSON (1983) cerca de 10\% dos animais tratados para superovulação não manifestam estro, e não apresentam nenhum crescimento folicular, o que não aconteceu neste trabalho.

O intervalo médio da aplicação da prostaglandina à manifestação do estro está de acordo com os dados de TAHIRA e HACKETT (1993), que observaram as manifestações estrais, em média, 47 horas após a aplicação do luteolítico.

O número de estruturas colhidas por vaca superovulada variou de 0 a 34 , demonstrando falta de uniformidade nas respostas ao tratamento, o que constitui um obstáculo a ser vencido para melhorar a eficiência do processo. O número e a qualidade das estruturas coletadas no $7^{\circ}$ ou $8^{\circ}$ dia após o estro estão contidos na Tabela 3 .

Tabela 2 - Intervalo da aplicação de prostaglandina $\left(\mathrm{PGF}_{2} \alpha\right)$ à manifestação do estro em novilhas superovuladas, tratadas com somatotropina bovina recombinante

Table 2 - Interval between prostaglandin $\left(P G F_{2} \alpha\right)$ injection and estrus in superovulated heifers, treated with recombinant bovine somatotropin

\begin{tabular}{lll}
\hline & \multicolumn{1}{c}{ T1* } & \multicolumn{1}{c}{ T2* } \\
\hline $\mathrm{P}^{\#}$ & $44,7 \mathrm{~h} \pm 7,6 \mathrm{~h}(\mathrm{n}=7)$ & $44,8 \mathrm{~h} \pm 9,3 \mathrm{~h}(\mathrm{n}=5)$ \\
$\mathrm{P}^{\#}$ & $40,8 \mathrm{~h} \pm 4,4 \mathrm{~h}(\mathrm{n}=6)$ & $44,1 \mathrm{~h} \pm 7,2 \mathrm{~h}(\mathrm{n}=5)$ \\
Média & $42,9 \mathrm{~h} \pm 6,4 \mathrm{~h}(\mathrm{n}=13)$ & $44,5 \mathrm{~h} \pm 7,9 \mathrm{~h}(\mathrm{n}=10)$ \\
Average & &
\end{tabular}

${ }^{*} \mathrm{~T} 1=$ animais recebendo $\mathrm{rbST}$ no $3^{\circ}$ dia do ciclo estral e $\mathrm{T} 2=$ controle.

\# $\mathrm{P} 1=$ período 1 = setembro/97 a dezembro/97 e $\mathrm{P} 2$ = período 2 = dezembro/97 a fevereiro/98.

${ }^{*} T 1=$ animals receiving rbST on day 3 of the estrus cycle and $T 2=$ control.

\#P1 $=$ period $1=$ September/97 to December $/ 97$ and $P 2=$ period $2=$ December $/$ 97 to February/98. 
Os efeitos positivos da utilização do rbST antes do tratamento superovulatório, com aumento do recrutamento folicular, do número de ovulações e de embriões recuperados (GRAY et al., 1993; GONG et al., 1993) e do número de embriões transferíveis (HERRLER et al., 1994), não foram verificados neste experimento.

Segundo RIEGER et al. (1991), as doses hormonais (rbST) necessárias para conseguir estimular os ovários deverão ser maiores que as utilizadas para aumentar a produção de leite. Como neste trabalho foi utilizada apenas uma dose (500 mg de sometribove), essa pode ter sido insuficiente para melhorar a resposta superovulatória. LUCY (1996) sugere a aplicação de três doses de rbST, com intervalos de quatorze dias, sendo que a primeira dose deve ser administrada cerca de sete dias antes do provável estro. Deste modo, seriam feitas duas aplicações durante a fase de crescimento folicular, e uma durante a fase de desenvolvimento embrionário.

As médias de estruturas coletadas nos tratamentos 1 e 2 foram de 15,3 e 17,4, respectivamente, com cerca de 8,5 e 11,5 embriões viáveis. O percentual de embriões avaliados como viáveis mostrou-se semelhante ao que foi encontrado por COELHO (1986) em animais da raça Nelore, inferiores aos de ELSDEN et al. (1978) e superiores aos de LINDNER e WRIGHT (1983). Estas diferenças podem ser devidas à variabilidade das respostas superovulatórias entre os animais de raças

Tabela 3 - Número médio de estruturas (total, $n^{\circ}$ de viáveis, não-viáveis e ovócitos) recuperadas de novilhas mestiças holandês-zebu tratadas com somatotropina bovina recombinante

Table 3 - Average number of structures (total, number of viable, non viable and oocytes) recovered from crossbred Holstein-Zebu heifers treated with bovine recombinant somatotrophin

\begin{tabular}{lcc}
\hline & $\begin{array}{c}\text { Somatotropina }(\mathrm{n}=12) \\
\text { Somatotropin }\end{array}$ & $\begin{array}{c}\text { Controle }(\mathrm{n}=8) \\
\text { Control }\end{array}$ \\
\hline Total & $15,3 \pm 9,5$ & $17,4 \pm 10,9$ \\
Viáveis & $8,5 \pm 8,3$ & $11,5 \pm 10,0$ \\
$\begin{array}{l}\text { Viable } \\
\text { Não-viáveis }\end{array}$ & $4,6 \pm 4,7$ & $3,4 \pm 1,3$ \\
$\begin{array}{l}\text { Non viable } \\
\text { Ovócitos }\end{array}$ & $2,2 \pm 2,8$ & $2,8 \pm 4,0$ \\
Oocytes & & \\
\hline
\end{tabular}

Valores não diferem $(\mathrm{P}>0,05)$.

Values did not differ $(P>.05)$. européias, zebuínas e seus cruzamentos, uma vez que diversos fatores como idade, raça (GALINA e ARTHUR, 1990), estação do ano e a presença de um folículo dominante no início do tratamento superovulatório (MONIAUX et al., 1983; LUSSIER e CARRUTHERS, 1989) podem comprometer a resposta ao tratamento superovulatório. As melhores respostas são obtidas quando o tratamento é iniciado no momento em que a população de folículos não atrésicos for máxima (DONALDSON,1984), o que ocorre entre os dias 0 e 5 e 9 e 13 do ciclo estral (MOOR et al., 1984). Como o tratamento superovulatório foi iniciado no dia 10 do ciclo estral das novilhas, as respostas inferiores podem ter sido devido à presença de um folículo dominante no início do tratamento, e que pertencia à segunda onda de crescimento folicular, quer seja nos ciclos estrais apresentando duas ou três ondas foliculares. Além disso, a dose e a atividade biológica da gonadotrofina utilizada são fatores que podem afetar a resposta superovulatória. Como os animais que não responderam ao tratamento apresentaram um bom crescimento folicular, porém sem ovulação, a dosagem hormonal pode ter sido maior que o necessário para uma resposta superovulatória positiva.

O número e o estádio de desenvolvimento embrionário após a coleta realizada entre o sétimo e o oitavo dia após a inseminação artificial estão relacionados na Tabela 4.

A maior taxa de estruturas coletadas no sétimo e oitavo dia encontravam-se nos estádios de mórula $(54,6$ e $34,5 \%)$ e blastocistos jovens (16,4 e 33,8\%), para os tratamentos 1 e 2, respectivamente. Estes dados são semelhantes aos de LINDNER e WRIGHT (1983), com coletas no sétimo dia. A menor ou maior porcentagem de um determinado estádio de desenvolvimento é uma função do dia em que a coleta foi realizada (SHEA, 1981), e da raça do animal utilizado. COELHO (1986) coletou embriões no sétimo dia e encontrou maior percentagem de mórula compacta e blastocisto jovem para os animais da subespécie $B o s$ taurus taurus, e mórula e mórula compacta em Bos taurus indicus. No oitavo dia predominaram blastocistos e blastocistos expandidos para os taurinos e mórula compacta e blastocistos jovens para os zebuínos. Estes dados demonstram que existe grande variabilidade individual no desenvolvimento e na qualidade embrionária, assim como variações entre as doadoras, podendo ocorrer diferenças de até 24 a 48 horas na idade dos embriões (LINDNER e 
Tabela 4 - Estádio de desenvolvimento das estruturas recuperadas de novilhas mestiças holandês-zebu, coletadas entre o sétimo e oitavo dia após o estro

Table 4 - Stage of development of structures recovered from crossbred holstein-zebu heifers, flushing on days 7 or 8 after estrus

\begin{tabular}{|c|c|c|c|c|c|c|}
\hline \multirow{2}{*}{$\begin{array}{l}\text { Estádio de } \\
\text { desenvolvimento } \\
\text { Stage of development }\end{array}$} & \multirow{2}{*}{$\begin{array}{c}\text { Somatotropina } \\
\text { Somatotropin } \\
(\mathrm{n}=12)\end{array}$} & \multicolumn{3}{|c|}{$\begin{array}{l}\text { Controle } \\
\text { Control }\end{array}$} & \multicolumn{2}{|c|}{$\begin{array}{l}\text { Total de estruturas } \\
\text { Total n. of structures }\end{array}$} \\
\hline & & $\%$ & $(\mathrm{n}=8)$ & $\%$ & $\mathrm{n}$ & $\%$ \\
\hline $\begin{array}{l}\text { Ovócitos } \\
\text { Oocytes }\end{array}$ & 26 & 14,2 & 22 & 15,8 & 48 & 14,9 \\
\hline $\begin{array}{l}\text { Mórulas } \\
\text { Morulae }\end{array}$ & 100 & 54,6 & 48 & 34,5 & 148 & 46,0 \\
\hline $\begin{array}{l}\text { Blastocisto jovem } \\
\text { Early blastocyst }\end{array}$ & 30 & 16,5 & 47 & 33,8 & 77 & 23,9 \\
\hline $\begin{array}{l}\text { Blastocisto } \\
\text { Blastocyst }\end{array}$ & 16 & 8,7 & 19 & 13,7 & 35 & 10,9 \\
\hline $\begin{array}{l}\text { Blastocisto expandido } \\
\text { Expanded blastocyst }\end{array}$ & 11 & 6,0 & 3 & 2,2 & 14 & 4,3 \\
\hline Total & 183 & 100,0 & 139 & 100,0 & 322 & 100,0 \\
\hline
\end{tabular}

Valores não diferem estatisticamente $(P>0,05)$.

Values did not differ $(P>05)$.

WRIGHT, 1983) e, deste modo, é importante considerar que o dia das coletas de embrião deve ser em função da raça do animal trabalhado.

\section{Conclusões}

O tratamento prévio de novilhas mestiças com dose única de $500 \mathrm{mg}$ de sometribove (rbST) no terceiro dia do ciclo estral não modificou a resposta superovulatória, no que se refere ao número e à viabilidade das estruturas coletadas no sétimo ou oitavo dia após a inseminação artificial.

\section{Agradecimento}

Às seguintes empresas, pela doação de seus produtos: Mallinckrodt Veterinary - Coopers do Brasil Ltda. (Ciosin); Fisons Industrial Ltda. (Anestésico PEARSON); Laboratórios Calier do Brasil Ltda. (Pluset); Nutricell - Nutrientes Celulares (Soluções para congelamento de embriões e DPBS 0,4\% BSA); Cultilab (Dulbecco Mod. DPBS e Soro fetal bovino); Tortuga(Bovigold); Sembra (Sêmen); Vallée (Aldazol Co e Controller CTO Pour On).

\section{Referências Bibliográficas}

ADASHI, E.Y., RESNICK, C.E., BRODIE, A M.H. et al. 1985a. Somatomedin C-mediated potentiation of follicle-stimulating hormone-induced aromatase activity of cultured rat granulosa cells. Endocrinology, 117:2313-2320.
ADASHI, E.Y., RESNICK, C.E., BRODIE, A M.H. et al. 1985b. Somatomedin $\mathrm{C}$ enhances induction of luteinizing hormone receptors by follicle-stimulating hormone in cultured granulosa cells. Endocrinology, 116:2369-2375.

BAUMAN, D.E. 1992 Bovine somatotropin: Review of an emerging animal technology. J. Dairy Sci., 75:3432-3451.

COELHO, E.N. Alguns aspectos da transferência de embriões em bovinos. Belo Horizonte, MG: Escola de Veterinária da UFMG, 1986. 83p. Dissertação (Mestrado em Medicina Veterinária) - Universidade Federal de Minas Gerais, 1986.

DONALDSON, L.E. 1983. The effects of $\mathrm{PGF}_{2} \alpha$ treatments in superovulated cattle on estrus response to embryo production. Theriogenology, 20:279-285.

DONALDSON, L.E. 1984. The day of the estrous cycle that FSH is started and superovulation in cattle. Theriogenology, 22(1):97-99.

ELSDEN, R.P., NELSON, L.D., SEIDEL JR., G.E. 1978. Superovulating cows with follicle stimulating hormone and pregnant mare's serum gonadotrophin. Theriogenology, 9(1):17-26.

ERICKSON, G.F., GARZO, V.G., MAGOFFIN, D. A. 1989. Insulin-like growth factor-I regulates aromatase activity in human granulosa luteal cells. J. Clin. Endocrinol. Metab. 69:716-724.

GALINA, C.S., ARTHUR, G.H. 1990. Review of cattle reproduction in the tropics. Part 5. Fertilization and pregnancy. Anim. Breed. Abstr., 58:805-813.

GLUCKMAN, P.D., BREIER, B.H., DAVIS, S.R. 1987. Physiology of the somatotropin axis with particular reference to the ruminant. J. Dairy Sci., 70:442-466.

GONG, J.G., BRAMLEY, T.A., WEBB, R. 1991. The effect of recombinant bovine somatotrophin on ovarian function in heifers: follicular populations and peripheral hormones. Biol. Reprod., 45:941-949.

GONG, J.G., BRAMLEY, T. A ., WILMUT, I. et al. 1993. Effect of recombinant bovine somatotropin on the superovulatory response to pregnant mare serum gonadotropin in heifers. Biol. Reprod., 48:1141-1149. 
GONG, J.G., McBRIDE, D., BRAMLEY, T.A. et al. 1994. Effects of recombinant bovine somatotrophin, insulin-like growth factor-I and insulin on bovine granulosa cell steroidogenesis in vitro. J. Endocrinology, 143:157-164.

GONG, J.G., WILMUT, I., BRAMLEY, T.A. et al. 1996 a. Pretreatment with recombinant bovine somatotropin enhances the superovulatory response to FSH in heifers. Theriogenology, 45:611-622.

GONG, J.G., WEBB, R. 1996. Control of ovarian follicle development in domestic ruminants: its manipulation to increase ovulation rate and improve reproductive performance. Anim. Breed. Abst., 64(3):195-204.

GRAY, B.D., STRINGFELLOW, D., RIDDELL, M. 1993. The effect of treatment with bovine somatotropin (BST) on the superovulatory response of cattle. Theriogenology, 39:227 (abstr.).

HAHN, J. 1992. Attempts to explain and reduce variability of superovulation. Theriogenology, 38:269-275.

HERRLER, A ., EINSPANIER, R., SCHAMS, D. 1994. Effect of recombinant bovine somatotrophin ( $\mathrm{rBST}$ ) on follicular IGF-I contents and the ovarian response following superovulatory treatment in dairy cows: a preliminary study. Theriogenology, 41:601-611.

HWANG, W.S., LEE, K.N., LEE, B.C. 1997. Effect of bST cotreatment with FSH or PMSG on transvaginal ultrasoundguided oocyte retrieval in calves. Theriogenology, 47(1):159 (abstr.).

KENNEDY, C.G., BOLAND, M.P., GORDON, I. 1983. The effect of embryo quality of freezing on subsequent development of thawed cow embryo. Theriogenology, 19:823-832.

LINDNER, G.M., WRIGTH, R.W. 1983. Bovine embryo morphology and evaluation. Theriogenology, 20(4):407-416.

LOBIE, P.E., BREIPOHL, W., ARAGON, J.G. et al. 1990. Cellular localization of the growth hormone receptor/binding protein in the male and female reproductive systems. Endocrinology, 126:2214-2221.

LUCY, C.M., COLLIER, R.J., KITCHELL, M.L et al. 1993a. Immunohistochemical and nucleic acid analysis of somatotropin receptor populations in the bovine ovary. Biol. Reprod., 48:1219-1227.

LUCY, M.C., De La SOTA, R.L., STAPLES, C.R. et al. 1993b. Ovarian follicular populations in lactating dairy cows treated with recombinant bovine somatotropin (Sometribove) or saline and fed diets differing in fat content and energy. J. Dairy Sci., 76(4):1014-1027.

LUCY, M.C. Use of bovine somatotropin to increase follicular growth in cattle: Applications to superovulation. In: ANNUAL CONVENTION OF AMERICAN EMBRYO TRANSFER ASSOCIATION, 15, Portland, Oregon, 1996. Proceedings... Portland, 1996. p.61-70.
LUSSIER, J.G., CARRUTHERS, T.D. 1989.Endocrine and superovulatory responses in heifers pretreated with FSH or bovine follicular fluid. Theriogenology, 31(4):779-794.

MONDSCHEIN, J.S., CANNING, S.F., MILLER, D.O. et al. 1989. Insulin-like growth factor (IGFs) as autocrine/paracrine regulators of granulosa cell differentiation and growth: studies with a neutralizing monoclonal antibody to IGF-I. Biol. Reprod., 40:79-85.

MONIAUX, D., CHUPIN, D., SAUMANDE, Y. 1983. Superovulatory response of cattle. Theriogenology, 19:58-81.

MOOR, R.M., KRUIP, T.A.M., GRESN,D. 1984. Intraovarian control of foliculogenesis: Limits to superovulation. Theriogenology, 21:103-116.

PAVLOK, A ., KOUTECKÁ, L., KREJCÍ, P., et al.1996. Effect of recombinant bovine somatotropin on follicular growth and quality of oocytes in cattle. Anim. Reprod. Sci., 41:183-192.

PINTO ANDRADE, L., RHIND, S.M., WRIGHT, I.A et al. 1996. Effect of bovine somatotrophin (bST) on ovarian function in post-partum beef cows. Reprod. Fertil. Dev., 8:951-960.

RIEGER, D., WALTON, J.S., GOODWIN, M.L. et al. 1991. The effect of co-treatment with recombinant bovine somatotropin on plasma progesterone concentration and number of embryos collected from superovulated Holstein heifers. Theriogenology, 35(5):863-869.

ROCHA, A., RANDEL, R.D., BROUSSARD, J.R. et al. 1998. High environmental temperature and humidity decrease oocyte quality in Bos taurus but not in Bos indicus cows. Theriogenology, 49(3):657-665.

TAHIRA, J.K., HACKETT, A.J. 1993. Superovulação de vacas canchin com FSH-P. Rev. Bras. Reprod. Anim., 17(1-2):41-47.

TANNER, J.W., HAUSER, S.D. 1989. Molecular evidence for the presence of the somatotropin receptor in the bovine ovary. J. Anim. Sci., 67 (suppl 1):413 (abst. 1001).

SHEA, B.F. 1981. Evaluating the bovine embryo. Theriogenology, 15(1):31-42.

WEBB, R., GONG, J.G., BRAMLEY, T.A. 1994. Role of growth hormone and intrafollicular peptides in follicle development in cattle. Theriogenology, 41:25-30.

WHITTINGHAN, D.G. 1971. Culture of mouse ova. J. Reprod. Fertil., 48(suppl.14):7-21.

Recebido em: 19/09/00

Aceito em: 18/05/01 